\title{
Políticas de avaliação da alfabetização: discutindo a Provinha Brasil*
}

ARTUR GOMES DE MORAIS

Universidade Federal de Pernambuco

\section{INTRODUÇÃO}

O que justificaria termos um exame nacional de monitoramento das aprendizagens realizadas por crianças que frequentam as redes públicas de ensino, no segundo ano de seu processo de alfabetização? Que limites e contribuições uma proposta de avaliação diagnóstica como a Provinha Brasil tem revelado, em suas primeiras edições? Em que precisamos avançar, para melhor avaliarmos o ensino e a aprendizagem de alfabetização praticados hoje em nosso país? Tendo já assumido, em trabalho anterior (Morais; Leal; Albuquerque, 2009), de forma explícita, uma posição favorável à realização de provas nacionais que mensurem a aprendizagem de nossos pequenos alfabetizandos, visamos, com o presente texto, colaborar com a discussão dessas três grandes questões.

Para isso, num primeiro momento, enfocaremos recentes mudanças que temos vivenciado nas concepções e práticas de alfabetização e que produziram o que Soares (2003) identificou como "desinvenção" da alfabetização. Assumindo, como aquela autora, a necessidade de uma "reinvenção" de nossas pedagogias de alfabetização, examinaremos como as críticas aos métodos tradicionais de alfabetização teriam produzido certa hegemonia dos discursos em torno da necessidade de letrar

* Uma primeira versão deste texto foi apresentada como trabalho encomendado no Grupo de Trabalho Alfabetização, Leitura e Escrita (GT-10), na 34a Reunião Anual da Associação Nacional de Pós-Graduação e Pesquisa em Educação (ANPEd), em outubro de 2011. 
nossos alunos e, paralelamente, incentivado certa ausência de sistemática no ensino da escrita alfabética, o que teria influenciado, inclusive, as propostas de ensino contidas nos novos "livros didáticos de alfabetização", substitutos das velhas cartilhas.

Ainda na perspectiva de perscrutar o pantanoso terreno em que se transformou o ensino do velho "bê-á-bá", discutiremos diferentes pesquisas que dão suporte à defesa de um monitoramento contínuo do processo de ensino-aprendizagem desenvolvido no início da educação fundamental. Tais investigações revelam a insegurança vivida pelos professores, nos últimos anos, sobre "como alfabetizar" e sobre como avaliar os progressos de seus alunos. No esteio de tais dificuldades, revisaremos os problemas detectados por alguns estudos, decorrentes da ausência de metas para cada ano dos "ciclos de alfabetização", a falta de progressão no ensino praticado em muitas salas de aula de redes públicas organizadas em ciclos e a generalizada ausência de atendimento à diversidade dos aprendizes, a qual, contraditoriamente, constitui princípio fundador de todos os atuais regimes de ensino organizados em ciclos. Ainda naquele bloco, examinaremos as dificuldades que, segundo diferentes pesquisas, nossos alfabetizadores têm vivenciado, quando se trata de avaliar seus alunos.

Num segundo momento, trataremos de evidências empíricas, produzidas e analisadas nos anos de 2010 e 2011, a partir do acompanhamento do ensino de alfabetização e do uso da Provinha em 12 salas de aula de três redes públicas municipais do estado de Pernambuco. Com base no estudo coordenado por Morais, Leal e Pessoa (2011), priorizaremos o exame do desempenho revelado pelos alunos nos itens da Provinha que mensuram a compreensão de leitura. Para melhor interpretarmos tais resultados, veremos que possíveis relações apresentam com as práticas de ensino de leitura observadas naquelas 12 salas de aula e com um exame qualitativo de itens das edições da Provinha, adotadas pelo Instituto Nacional de Estudos e Pesquisas Educacionais Anísio Teixeira (INEP)-Ministério da Educação (MEC) em 2010.

Concluiremos defendendo a necessidade de assumirmos, com urgência, a discussão de duas questões fundamentais. Por um lado, que façamos um debate explícito sobre os currículos de alfabetização que queremos adotar em nossas redes públicas de ensino. Por outro lado, que cobremos das instâncias responsáveis uma discussão aberta e ampliada sobre os exames de avaliação em larga escala como a Provinha, na qual possamos negociar tanto questões de concepção (propósitos da avaliação, matrizes de referência) como as formas de aplicá-los e utilizá-los em nossas redes públicas.

\section{COMO ESTAMOS ALFABETIZANDO NOSSAS CRIANÇAS? AS EVIDÊNCIAS DE UMA DESINVENÇÃO DA ALFABETIZAÇÃO E DA NECESSIDADE DE REINVENTÁ-LA}

Como mencionamos na seção anterior, concordamos com Soares (2003), quando essa autora interpreta que, no caso brasileiro, a partir dos anos de 1980, começamos a viver um processo de "desinvenção" da alfabetização. Ante as propostas 
de negação do "ensino tradicional" (centrado nos métodos de alfabetização veiculados por cartilhas), vivemos um amplo debate sobre o que fazer para desenvolver nos aprendizes práticas letradas de leitura e produção textuais e alfabetizar "segundo o construtivismo" e, depois, numa "perspectiva de letramento". Mas, como afirmamos em outra ocasião (Morais, 2006), a negação aos métodos tradicionais se fez acompanhar, em muitos casos, de um não tratamento da escrita alfabética como um objeto de ensino e aprendizagem em si e da expectativa de que, espontaneamente, pela participação exclusiva em atividades de leitura e produção de textos, as crianças viessem a se alfabetizar. Em nome do construtivismo, criou-se um grande estado de indefinição sobre o que ensinar e como ensinar nas salas de aula de alfabetização.

A fim de conhecer e compreender o que, de fato, nossas alfabetizadoras têm praticado com suas turmas, Albuquerque, Morais e Ferreira (2008) desenvolveram uma pesquisa com um grupo de nove professoras que lecionavam no $1^{\circ}$ ano do $1^{\circ}$ ciclo da Secretaria de Educação da cidade do Recife. Como procedimentos metodológicos, além de observações semanais das aulas das professoras, uma vez por mês eram realizados encontros de grupo focal, que tinham o objetivo de discutir as práticas observadas e refletir sobre alguns aspectos constitutivos do processo de alfabetização. A análise dos resultados revelou que um subgrupo de professoras desenvolvia, sim, uma prática diária de ensino, que contemplava, de segunda a sexta-feira, tanto atividades de reflexão sobre o sistema de escrita alfabética como atividades de leitura e produção de textos. Um outro subgrupo de professoras priorizava o trabalho de leitura e produção coletiva de textos, sem ensinar o sistema alfabético. A realização de uma avaliação, ao final do ano letivo, com os alunos daquelas professoras mostrou que a maioria das crianças que estudavam com as do primeiro grupo concluiu o ano na hipótese alfabética de escrita, enquanto, nos outros grupos, menos da metade dos alunos apresentou hipóteses de escrita naquele nível (Albuquerque; Ferreira; Morais, 2006).

Outras pesquisas buscaram analisar o ensino da leitura e da escrita nos três primeiros anos do $1^{\circ}$ ciclo. As pesquisas de Oliveira $(2006,2010)$ demonstram como, nas redes públicas organizadas em ciclos, muitas escolas persistem adotando uma tendência a adiar (para as idades de 7 ou 8 anos) a expectativa de que as crianças dominem a escrita alfabética. Nesses estudos, ficou evidente uma ausência de metas ou expectativas de aprendizagem para cada um dos três anos do ciclo de alfabetização. Na pesquisa de 2010, Oliveira constatou que essa ausência de metas provocava uma grande falta de progressão no que se ensinava ao longo do ciclo na área de língua portuguesa. Verificou também que, nas nove turmas, em que acompanhou 72 jornadas escolares, eram raríssimas as iniciativas para atender às necessidades dos alunos com mais dificuldades em se alfabetizar. $\mathrm{O}$ ensino tendia a ser padronizado, com atividades propostas para o coletivo das turmas, e os alunos com mais baixo rendimento tendiam a excluir-se delas.

Ajudando-nos a compreender as consequências desse quadro de realidade, Cruz (2008) e Cruz e Albuquerque (2011) realizaram um estudo que teve como objetivo verificar a apropriação da escrita por alunos do $1^{\circ}$ ciclo, tanto no que se refere ao domínio do Sistema de Escrita Alfabética (SEA) quanto à capacidade de produzir textos. Participaram da pesquisa 60 alunos ( 15 do $1^{\circ}$ ano, 20 do $2^{\circ}$ ano e 25 do $3^{\circ}$ ano) de uma escola da rede municipal de ensino do Recife. As autoras constataram que a maioria dos 
alunos das três turmas concluiu o ano na fase alfabética de escrita, apresentando razoável domínio das correspondências som-grafia diretas. No entanto, quanto à produção textual, as crianças do $1^{\circ}$ ano apresentaram um desempenho melhor que as dos outros anos. Esses resultados revelam, por um lado, a falta de definição de metas específicas para cada ano do $1^{\circ}$ ciclo. Por outro lado, apontam para a possibilidade de alunos do $1^{\circ}$ ano do $1^{\circ}$ ciclo se apropriarem do SEA, ao mesmo tempo em que ampliam suas experiências de letramento, desde que sejam submetidos a atividades sistemáticas de alfabetização que os levem a refletir sobre o SEA, assim como a atividades de leitura e produção de textos.

Além das grandes variações nas formas de alfabetizar, estudos recentes têm sugerido que os alfabetizadores têm dificuldades em avaliar os progressos realizados por seus alunos e de basearem o ensino de alfabetização nas informações derivadas daquelas avaliações.

Alguns dos estudos demonstram que os professores passaram a buscar diagnosticar periodicamente os "níveis de escrita" descritos pela teoria da psicogênese da escrita. Mamede (2003) verificou que professoras cearenses atribuíam importância a aplicar-se o "ditado de quatro palavras e uma oração" no início, no meio e no final do ano, porque a partir dele seria possível ver "uma diferença enorme" no desempenho dos alunos. As mestras não cogitavam, contudo, que poderiam obter o mesmo tipo de informação por meio de análises de escritas espontâneas, no dia a dia.

Na esteira de usos de diagnóstico de níveis de escrita, Monteiro (2004) refletiu sobre como os docentes, mesmo usando textos espontâneos variados, podem viver um dilema a partir de certa apropriação da mesma teoria psicogenética. Segundo tal apropriação, os docentes passariam a crer que o aluno "tem que aprender tudo sozinho" (tal como também assinalou Mamede, 2003, p. 7) e que "não existe erro no que o aprendiz escreve", o que os levaria a se omitir de ensinar e que os faria transmitir para os alunos a ideia de que para o professor "tudo o que fazem está certo" (idem, ibidem).

Ainda quanto ao uso do ditado de "quatro palavras e uma oração", Cunha (2005) observou que as contribuições trazidas por esse instrumento se restringiam à classificação das crianças em níveis. Não constituía, portanto, uma ferramenta de que o professor se valesse para planejar intervenções que conduzissem o aluno a viver conflitos sobre suas hipóteses e reelaborá-las, aproximando-se, cada vez mais, da escrita convencional.

No que concerne ao tratamento dado à avaliação por alfabetizadoras que atuam em redes públicas organizadas no sistema de ciclos, o estudo de Oliveira (2006) demonstra que as mestras indicavam estar apropriando-se de um conjunto de princípios que balizam uma perspectiva de "avaliação formativa". Elas afirmavam avaliar "por meio da observação contínua" e/ou da "análise das produções escritas dos educandos", embora tivessem dificuldade em explicitar verbalmente "o que" era continuamente observado. Com o novo regime de ciclos, as alfabetizadoras teriam passado a registrar, mais qualitativamente, no diário de classe, os progressos dos alunos. Essa nova empreitada era vivida de forma conflitiva - já que a secretaria de ensino onde atuavam não tinha definido expectativas de aprendizagem para os alfabetizandos durante os 
três anos do $1^{\circ}$ ciclo - e as docentes, por conta própria, é que se reuniam para definir parâmetros do que iriam registrar como competências desenvolvidas pelos alunos.

Apesar de aquelas mestras dizerem ser fundamental a "comparação da evolução do aluno na construção do conhecimento”, tal concepção coexistia com a prática de comparar o aluno com outra criança da turma e não com os conhecimentos por ele construídos ao longo do ano (idem). A autora também constatou que quatro das nove professoras por ela pesquisadas usavam provas e testes junto à avaliação contínua.

Do ponto de vista institucional, assim como as docentes estudadas por Frigotto (2005), as alfabetizadoras acompanhadas por Oliveira eram contra a promoção automática e criavam táticas de inclusão e exclusão dos alunos avaliados como "com dificuldades". No primeiro caso, por exemplo, professoras colegas de ciclo criavam, em certos dias e horários da semana, "reenturmações" de alunos com níveis semelhantes, a fim de atendê-los mais adequadamente, já que a secretaria de educação não tinha nenhuma estratégia para ensinar àqueles estudantes. No segundo caso (táticas de exclusão), as professoras atribuíam faltas aos alunos que chegavam atrasados, para poder reprová-los, ou matriculavam o aluno na série "correta" (sem reprová-1o), mas o colocavam para assistir aulas em turma do mesmo ano do $1^{\circ}$ ciclo que o aluno tinha cursado no ano anterior.

Mundo, mundo, vasto mundo... Entendemos que as investigações agora revisadas apontam para um quadro de grandes variações (ou indefinições?) no que diz respeito ao ensino e à avaliação na alfabetização. Assumindo uma perspectiva de avaliação formativa (Fernandes, 2006), e sem confundir avaliação com exame (Esteban, 2009), temos defendido a urgência de monitorarmos o que nossos aprendizes vão reconstruindo de conhecimentos sobre a língua escrita e sobre sua notação, ao longo dos anos iniciais do ensino fundamental (Morais; Leal; Albuquerque, 2009). Desde as discussões iniciais que redundaram na criação da Provinha Brasil, julgávamos que tal exame, assumindo uma perspectiva estritamente diagnóstica, poderia constituir-se num importante instrumento para os envolvidos na tarefa de "reinventar a alfabetização em nosso país" (Soares, 2003). Nosso envolvimento com a Provinha nos fez desenvolver a pesquisa de que trataremos nas seções seguintes.

\section{NOSSA PESQUISA SOBRE A PROVINHA: SEUS OBJETIVOS, AS PROFESSORAS E OS ALUNOS ENVOLVIDOS E NOSSOS PROCEDIMENTOS DE COLETA DE DADOS}

A fim de contribuir para a análise das formas como a Provinha Brasil vem sendo recebida pelas redes públicas, e melhor compreender seus impactos, contribuições e limites, a equipe do Centro de Estudos em Educação e Linguagem da Universidade Federal de Pernambuco (CEEL-UFPE) (Morais; Leal; Pessoa, 2011), ao assumir uma tarefa de cooperação com o INEP, comprometeu-se a realizar uma pesquisa, constituída de dois subprojetos, intitulados:

\section{Provinha Brasil: sua recepção por professores e gestores e seus impactos no ensino de alfabetização; e}


II. Provinha Brasil: conhecimentos dos alunos que o teste avalia e outros conhecimentos que poderia avaliar.

O primeiro subprojeto, como seu nome sugere, visou identificar os modos como professores e gestores (diretores, coordenadores pedagógicos) ligados a turmas de alfabetização (do $2^{\circ}$ ano do ensino fundamental) concebiam e utilizavam a Provinha no diagnóstico de conhecimentos dos alfabetizandos e no planejamento do ensino de alfabetização. Visava também analisar a evolução dos conhecimentos infantis mensurados pela Provinha e comparar tais conhecimentos com o ensino recebido pelas crianças, ao longo do ano letivo.

O segundo subprojeto tinha por objetivos:

1- Identificar que conhecimentos os alfabetizandos revelavam sobre o SEA e sobre práticas de leitura, que são avaliados pela Provinha;

2- Identificar que outros conhecimentos, sobre o SEA e sobre a competência de produzir textos, os alfabetizandos revelavam quando submetidos a outros instrumentos que não a Provinha; e

3- Relacionar os dois tipos de evidências e discutir o quanto auxiliariam o professor alfabetizador a planejar um ensino ajustado às necessidades dos alunos.

Ante a grande amplidão dos dados coletados, no presente texto priorizaremos algumas das evidências empíricas obtidas com as professoras e alunos envolvidos. Antes de apresentá-las, faremos uma breve apresentação dos participantes e dos procedimentos de coleta de dados.

No Subprojeto I (Provinha Brasil: sua recepção por professores e gestores e seus impactos no ensino de alfabetização), nossos informantes eram profissionais de três redes municipais de ensino (Camaragibe, Jaboatão e Recife), situadas na região metropolitana do Recife. Em cada rede tivemos informantes de duas ou três escolas, totalizando, em cada município, quatro professoras do $2^{\circ}$ ano do $1^{\circ}$ ciclo. ${ }^{1}$

As escolas participantes estavam entre aquelas que, na edição da Prova Brasil anterior à nossa pesquisa, tinham obtido, em seus municípios, melhores resultados, quando comparadas às demais unidades de ensino. Nossa intenção, portanto, foi compreender os modos de conceber e usar a Provinha por estabelecimentos que, em princípio, ofereceriam uma educação de qualidade à população. Noutras palavras, não nos interessava fazer radiografia do caos.

Os Quadros 1 e 2 apresentam, de forma resumida, o perfil das professoras entrevistadas.

1 Embora não venhamos a discutir os dados obtidos com gestores, também participaram da pesquisa três ou quatro gestores (coordenadores pedagógicos ou diretores) de cada município pesquisado. 
Quadro 1 - Perfil das professoras - formação

\begin{tabular}{|c|c|c|c|c|c|c|c|}
\hline .을 & Prof. & $\begin{array}{c}\text { Magistério } \\
\text { Ensino } \\
\text { Médio }\end{array}$ & Graduação & $\begin{array}{c}\text { Instituição } \\
\text { Ensino } \\
\text { Superior }\end{array}$ & $\begin{array}{c}\text { Ano } \\
\text { conclusão/ } \\
\text { graduação }\end{array}$ & $\begin{array}{c}\text { Pós- } \\
\text {-graduação }\end{array}$ & $\begin{array}{c}\text { Ano } \\
\text { conclusão } \\
\text { pós }\end{array}$ \\
\hline \multirow{4}{*}{ 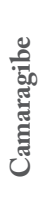 } & $\mathrm{C} 1$ & $\operatorname{sim}$ & pedagogia & pública & 2008 & $\operatorname{sim}$ & cursa \\
\hline & $\mathrm{C} 2$ & $\operatorname{sim}$ & pedagogia & pública & 2002 & não & - \\
\hline & $\mathrm{C} 3$ & $\operatorname{sim}$ & pedagogia & privada & 1998 & $\operatorname{sim}$ & 2004 \\
\hline & $\mathrm{C} 4$ & $\operatorname{sim}$ & pedagogia & pública & 2002 & $\operatorname{sim}$ & cursa \\
\hline \multirow{4}{*}{ 范 } & R1 & não & pedagogia & pública & 2006 & $\operatorname{sim}$ & cursa \\
\hline & R2 & $\operatorname{sim}$ & pedagogia & privada & 1996 & não & - \\
\hline & R3 & não & pedagogia & privada & 1984 & não & - \\
\hline & $\mathrm{R} 4$ & $\operatorname{sim}$ & letras & pública & 1983 & $\operatorname{sim}(2)$ & $1992 / 2005$ \\
\hline \multirow{4}{*}{ 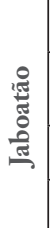 } & $\mathrm{J} 1$ & $\operatorname{sim}$ & pedagogia & pública & 2003 & $\operatorname{sim}$ & 2006 \\
\hline & $\mathrm{J} 2$ & $\operatorname{sim}$ & $\begin{array}{c}\text { história } \\
\text { pedagogia }\end{array}$ & $\begin{array}{l}\text { privada } \\
\text { privada }\end{array}$ & $\begin{array}{l}1999 / \\
2005\end{array}$ & $\operatorname{sim}$ & cursa \\
\hline & $\mathrm{J} 3$ & $\operatorname{sim}$ & pedagogia & privada & cursa & - & - \\
\hline & $\mathrm{J} 4$ & $\operatorname{sim}$ & pedagogia & pública & 2007 & $\operatorname{sim}$ & cursa \\
\hline
\end{tabular}

Fonte: Dados da pesquisa.

Elaboração do autor.

Quadro 2 - Perfil das professoras - experiência profissional

\begin{tabular}{|c|c|c|c|c|c|c|c|c|c|c|}
\hline \multirow{2}{*}{\begin{tabular}{|l|} 
을 \\
을 \\
产
\end{tabular}} & \multirow[b]{2}{*}{ Prof. } & \multirow{2}{*}{$\begin{array}{l}\text { Anos } \\
\text { de } \\
\text { ensino }\end{array}$} & \multirow{2}{*}{$\begin{array}{c}\text { Anos } \\
\text { na rede }\end{array}$} & \multicolumn{3}{|c|}{ Série / ano } & \multirow{2}{*}{$\begin{array}{c}\text { Trabalha } \\
\text { mesma escola } \\
\text { (outro turno) }\end{array}$} & \multirow{2}{*}{$\begin{array}{c}\text { Trabalha } \\
\text { em outra } \\
\text { escola }\end{array}$} & \multirow{2}{*}{$\begin{array}{c}\text { Rede da } \\
\text { outra } \\
\text { escola }\end{array}$} & \multirow{2}{*}{$\begin{array}{c}\text { Outra } \\
\text { atividade } \\
\text { profissional }\end{array}$} \\
\hline & & & & 2007 & 2008 & 2009 & & & & \\
\hline \multirow{4}{*}{ 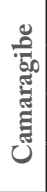 } & $\mathrm{C} 1$ & 8 & 8 & 3 & $1 / 1$ & $2 / 1$ & $\operatorname{sim}$ & não & - & não \\
\hline & $\mathrm{C} 2$ & 24 & 24 & 1 & $2 / 1$ & $2 / 1$ & $\operatorname{sim}$ & não & - & não \\
\hline & $\mathrm{C} 3$ & 16 & 2 & 3 & $2 / 1$ & $3 / 1$ & não & $\operatorname{sim}$ & municipal & não \\
\hline & $\mathrm{C} 4$ & 8 & 8 & $3 / 1$ & $2 / 1$ & $2 / 1$ & não & $\operatorname{sim}$ & municipal & não \\
\hline \multirow{4}{*}{ 幽 } & R1 & 1 & $3 m$ & - & - & $2 / 1$ & não & não & - & $\operatorname{sim}$ \\
\hline & $\mathrm{R} 2$ & 30 & 21 & 5 & $1 / 1$ & $2 / 1$ & não & $\operatorname{sim}$ & estadual & não \\
\hline & R3 & 24 & 20 & 3 & EI & EI & não & $\operatorname{sim}$ & estadual & não \\
\hline & $\mathrm{R} 4$ & 18 & 7 & $\mathrm{EI}$ & EI/EI & $2 / 1$ & กล̃o & $\operatorname{sim}$ & estadual & não \\
\hline \multirow{4}{*}{ 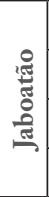 } & $\mathrm{J} 1$ & 11 & 7 & 2 & 2 & 2 & não & $\operatorname{sim}$ & pública & não \\
\hline & $\mathrm{J} 2$ & 19 & 6 & 3 & 1 & 1 & não & $\operatorname{sim}$ & pública & $\operatorname{sim}$ \\
\hline & $\mathrm{J} 3$ & 10 & 2 & EI & 1 & 1 & não & $\operatorname{sim}$ & privada & $\operatorname{sim}$ \\
\hline & $\mathrm{J} 4$ & 27 & 27 & 3 & 3 & 2 & não & $\operatorname{sim}$ & pública & não \\
\hline
\end{tabular}

Fonte: Dados da pesquisa.

Elaboração do autor. 
Como se pode depreender, todas as professoras possuíam diploma de graduação e 7/12 a tinham cursado em instituição pública. Dez das 12 participantes tinham se graduado em pedagogia e oito delas cursavam pós-graduação ou já a haviam concluído.

Também eram, em sua maioria (11/12), profissionais experientes, com oito ou mais anos de atuação como docentes. A maioria possuía experiência específica em alfabetização (turmas equivalentes a $1^{\circ}, 2^{\circ}$ e $3^{\circ}$ anos), em especial no ano anterior à pesquisa (então, 11 das 12 professoras eram alfabetizadoras). Além disso, 11 professoras trabalhavam nos dois turnos, sendo que duas delas o faziam na mesma escola e as demais, em escolas diferentes. Apenas três professoras tinham outras atividades profissionais, além da docência.

Fizemos também um breve perfil das crianças, apresentado no Quadro 3, que permite concluir que a maioria das turmas tinha menos que 25 alunos, que estes, via de regra, não haviam sofrido repetência anterior (exceto no caso de um município) e que suas idades médias variavam entre 7 anos e um mês a 8 anos e meio. A proporção de alunos que tinha feito o $1^{\circ}$ ano do ensino fundamental na mesma escola em que estava estudando em 2010 variou bastante entre os municípios.

\section{Quadro 3 - Perfil dos alunos que participaram durante todo o ano letivo}

\begin{tabular}{|c|c|c|c|c|c|c|}
\hline \multirow{2}{*}{ Município } & \multirow{2}{*}{ Turma } & \multirow{2}{*}{$\begin{array}{c}\text { Total } \\
\text { de alunos }\end{array}$} & \multirow{2}{*}{$\begin{array}{l}\text { Idade } \\
\text { média }\end{array}$} & \multirow{2}{*}{$\begin{array}{c}\text { Estudavam na } \\
\text { escola em } 2009\end{array}$} & \multicolumn{2}{|c|}{ Repetente } \\
\hline & & & & & SIM & NÃO \\
\hline \multirow{4}{*}{ Camaragibe } & 1 & 20 & 7,3 & 20 & 5 & 15 \\
\hline & 2 & 10 & 8,5 & 8 & 4 & 6 \\
\hline & 3 & 13 & 7,5 & 13 & - & 13 \\
\hline & 4 & 20 & 7,5 & 19 & 4 & 16 \\
\hline \multirow{4}{*}{ Recife } & 1 & 27 & 7,4 & 0 & 1 & 26 \\
\hline & 2 & 30 & 7,3 & 18 & - & 30 \\
\hline & 3 & 15 & 7,4 & 10 & - & 15 \\
\hline & 4 & 18 & 7,6 & 13 & 1 & 17 \\
\hline \multirow{4}{*}{ Jaboatão } & 1 & 22 & 7,2 & 21 & - & 22 \\
\hline & 2 & 25 & 7,4 & 23 & - & 25 \\
\hline & 3 & 14 & 8,5 & 7 & - & 14 \\
\hline & 4 & 11 & 7,6 & 9 & - & 11 \\
\hline
\end{tabular}

Fonte: Dados da pesquisa.

Elaboração do autor.

No Subprojeto I, nossa coleta de dados envolveu, além de entrevistas semiestruturadas com as docentes e os dirigentes, no início e no final do ano letivo, o acompanhamento, por meio de observação, da aplicação da Provinha, em cada escola, em cada uma das turmas. Gravamos e transcrevemos os comandos dados pelos professores e as verbalizações dos alunos, durante a aplicação da Provinha. O mesmo procedimento foi realizado no mês de novembro de 2011.

Além disso, acompanhamos, durante o ano letivo, as ações de ensino nas 12 turmas que fizeram parte da pesquisa. A cada mês, de março a novembro, fizemos visitas a cada uma das 12 turmas, para observar e registrar uma jornada completa de aula. Em 
tais observações (nove em cada turma, totalizando 108 para as 12 turmas), registrávamos todas as atividades desenvolvidas pelas docentes com as crianças, o tempo dedicado a cada atividade, o tratamento dado à heterogeneidade (existência ou não de atividades diferenciadas para alunos diagnosticados com diferentes níveis de aprendizagem) e as formas de organização das crianças (trabalho individual, duplas, coletivo etc.).

Nas seções seguintes, selecionaremos algumas das evidências empíricas obtidas e analisadas. Centraremos nossa análise no ensino e na aprendizagem das habilidades envolvidas na compreensão leitora. De início, faremos uma análise do ensino de leitura de textos, que pudemos acompanhar nas 108 jornadas de aula observadas, de março a novembro. Buscaremos, em seguida, relacionar tal ensino ao desempenho em compreensão leitora mensurado pelas edições da Provinha a que os alunos responderam no início e no final do ano letivo. Num terceiro momento, faremos uma análise da complexidade de itens que, em cada uma daquelas edições da Provinha, se propunham a avaliar habilidades ("descritores") de compreensão leitora.

\section{EVIDÊNCIAS EMPÍRICAS 1 - ANÁLISE DAS PRÁTICAS DE LEITURA OBSERVADAS NAS 12 SALAS DE AULA}

Nossa análise priorizou o exame de quais modalidades de leitura foram praticadas nas 12 salas de aula, nos dias em que as observamos, durante o ano letivo, bem como dos tipos de estratégias de leitura que as crianças exercitaram naqueles dias. Os dados do primeiro tipo - modalidades de práticas de leitura - aparecem sistematizados na Tabela 1.

Tabela 1 - Modalidades de leitura de textos e de enunciados observadas nas 12 turmas de alfabetização, ao longo do ano letivo (nove observações em cada turma)

\begin{tabular}{l|r|r|r|r|r|r|r|r|r|r|r|r|r|r|r}
\hline & C1 & C2 & C3 & C4 & Tot & R1 & R2 & R3 & R4 & Tot & J1 & J2 & J3 & J4 & Tot \\
\hline $\begin{array}{l}\text { Leitura de enunciado } \\
\text { pela professora }\end{array}$ & 6 & 4 & 4 & 4 & $\mathbf{1 8}$ & 6 & 2 & 8 & 2 & $\mathbf{1 8}$ & 2 & 7 & 6 & 3 & $\mathbf{1 8}$ \\
\hline $\begin{array}{l}\text { Leitura de enunciado } \\
\text { pelo aluno }\end{array}$ & 1 & 1 & 2 & 2 & $\mathbf{6}$ & - & 2 & - & - & 2 & 7 & 4 & 3 & 1 & $\mathbf{1 5}$ \\
\hline $\begin{array}{l}\text { Interpretação } \\
\text { oral de texto }\end{array}$ & 2 & 1 & - & 1 & 4 & 5 & 3 & 1 & 2 & $\mathbf{1 1}$ & 1 & 5 & - & - & $\mathbf{6}$ \\
\hline $\begin{array}{l}\text { Interpretação } \\
\text { escrita de texto }\end{array}$ & - & - & - & - & - & 3 & 1 & 3 & 3 & $\mathbf{1 0}$ & - & - & - & - & - \\
\hline $\begin{array}{l}\text { Leitura de texto } \\
\text { pelo aluno }\end{array}$ & 1 & 2 & 4 & 1 & $\mathbf{8}$ & 3 & 1 & - & 5 & $\mathbf{9}$ & 3 & 5 & 1 & - & $\mathbf{9}$ \\
\hline $\begin{array}{l}\text { Leitura de texto } \\
\text { pela mestra }\end{array}$ & 7 & 2 & 2 & 3 & $\mathbf{1 4}$ & 9 & 4 & 7 & 3 & $\mathbf{2 3}$ & 4 & 6 & 2 & 2 & $\mathbf{1 4}$ \\
\hline $\begin{array}{l}\text { Leitura de texto } \\
\text { coletiva }\end{array}$ & 2 & 2 & 6 & 2 & $\mathbf{1 2}$ & 1 & 2 & 4 & 2 & $\mathbf{9}$ & - & 2 & - & - & $\mathbf{2}$ \\
\hline $\begin{array}{l}\text { Leitura silenciosa } \\
\text { pelos alunos }\end{array}$ & 2 & - & 3 & 1 & $\mathbf{6}$ & - & 7 & 5 & 1 & $\mathbf{1 3}$ & 2 & 1 & - & - & $\mathbf{3}$ \\
\hline $\begin{array}{l}\text { Leitura livre } \\
\text { pelos alunos }\end{array}$ & - & - & 1 & - & $\mathbf{1}$ & 1 & - & - & - & $\mathbf{1}$ & - & - & - & - & - \\
\hline
\end{tabular}

$\mathrm{C}=$ turmas de Camaragibe; $\mathrm{R}=$ turmas de Recife; $\mathrm{J}=$ turmas de Jaboatão.

Número máximo de ocorrências em cada célula de turma = 9; Número máximo de ocorrências no total de cada município = 36 . Fonte: Dados da pesquisa.

Elaboração do autor. 
O exame da Tabela 1 atesta que, durante o $2^{\circ}$ ano do $1^{\circ}$ ciclo, a ocorrência de leitura de textos e enunciados variou muito entre as turmas. Assim, se houve um grupo-classe em que a mestra leu textos em todos os dias observados, em um terço das turmas isso só ocorreu em duas das nove aulas que acompanhamos. Enfim, mesmo no interior de cada município, encontramos bastante variação na proporção de dias em que houve leituras de enunciados e leitura de textos, o que parece um primeiro indicador da ausência de uma proposta comum, em cada rede de ensino, quanto ao tratamento didático-pedagógico a ser dispensado ao eixo curricular "leitura e compreensão de textos", num mesmo ano do $1^{\circ}$ ciclo.

Uma segunda evidência que nos chama a atenção é o fato de que os alunos fizeram bem menos vezes que suas mestras a leitura individual de textos em voz alta. $\mathrm{Na}$ grande maioria das turmas, as ocasiões em que as professoras leram textos ou enunciados ocorreram numa proporção bem superior àquelas em que cabia aos alunos fazê-lo. Se numa das salas de aula (J4) nunca presenciamos a leitura de texto pelas crianças, só numa turma (J2) tal solicitação ocorreu em um pouco mais da metade das aulas que acompanhamos. Essa tendência a que as docentes monopolizassem as leituras individuais em voz alta foi também constatada por Oliveira (2010), numa pesquisa longitudinal, em que acompanhou nove turmas dos três primeiros anos do ensino fundamental de uma rede pública de ensino.

Tendo em vista que em muitos de nossos grupos-classe a leitura coletiva de textos não ocorreu de forma mais expressiva que a leitura individual pelos alunos, configura-se um cenário no qual os alunos tinham pouco espaço para ler, oralizando textos. Seria possível pensar que a reduzida prática de tais modalidades de leitura (em voz alta, individual e coletiva) pelos alunos se devesse a uma substituição delas pela leitura silenciosa. Não foi, de modo algum, o que constatamos. Na realidade, na grande maioria das turmas, eram ausentes ou raras as situações em que os aprendizes eram chamados a ler, silenciosamente, um texto. Esse dado parece-nos exigir duas reflexões.

Em primeiro lugar, fica patente a falta de familiaridade dos estudantes com as situações de leitura silenciosa de textos, tal como tendem a ser exigidas nas avaliações de larga escala, que aferem o desempenho de compreensão leitora, entre elas a Provinha Brasil. Sendo mais explícitos, é possível que, em algumas turmas (como é o caso de quatro das que acompanhamos), os alunos nunca ou quase nunca vivessem, fora dos dias de aplicação da Provinha, o que é ler textos sozinhos, em silêncio, para, em seguida, responder a questões escritas sobre esses textos. Obviamente não vemos nenhum ganho para os aprendizes em não experimentar tal modalidade de leitura e de exercícios para aprender a compreender textos escritos.

Em segundo lugar, é intrigante o fato de que, no $2^{\circ}$ ano do $1^{\circ}$ ciclo, na maioria dos grupos-classe, mesmo os alunos que já dominassem as convenções da escrita alfabética fossem impedidos de vivenciar a leitura silenciosa de textos. Se juntarmos a isso o predomínio de ocorrência de situações em que as próprias mestras liam em voz alta textos para seus alunos, concluímos que, mesmo ao final do segundo ano de alfabetização, talvez aqueles aprendizes tivessem poucas oportunidades de, em sala de aula, exercer, de forma minimamente autônoma, a leitura completa de um texto, em silêncio. 
O exame da ocorrência de atividades de "interpretação" ou "compreensão" de textos não traz informações mais animadoras para o cenário que encontramos. $\mathrm{O}$ exame da Tabela 1 revela que o número de dias em que se praticou oralmente ou por escrito qualquer atividade de interpretação/compreensão foi muito pequeno, surpreendentemente inferior, na maioria das turmas, ao número de ocasiões em que havia leitura de textos (pelas mestras ou pelos alunos). Isso nos dá uma indicação inicial de que atividades que pudessem promover a compreensão leitora tendiam a ser, independentemente de sua qualidade, escassas. Infelizmente, em três das nove turmas observadas, não presenciamos quaisquer atividades desse tipo.

Cabe enfatizar que foram ainda mais raros os dias letivos em que, após a leitura de um texto, os alunos realizassem, na forma escrita, algum tipo de atividade de compreensão leitora. À exceção de uma rede municipal (Recife) em que tal prática ocorreu numa proporção (10/36 dias) idêntica à de "interpretação oral" (11/36 dias), nos outros dois municípios nunca presenciamos a realização de exercícios escritos de compreensão de leitura.

Novamente, algumas considerações nos parecem obrigatórias. A não realização de tarefas escritas de compreensão dos textos nos parece uma opção das docentes. Interpretamos que as professoras teriam preferido excluir tais tarefas do processo de alfabetização, já que os livros didáticos usados em suas turmas e aprovados pelo Programa Nacional do Livro Didático (PNLD) necessariamente propunham, a cada lição ou unidade didática, atividades desse tipo, após a leitura dos textos (literários, informativos, jornalísticos etc.) que os alunos seriam chamados a ler. Ao mesmo tempo, mais uma vez fica patente a baixa familiaridade dos aprendizes com o formato dos itens da Provinha Brasil, com as questões que nela avaliam a compreensão leitora, em virtude do tipo de ensino recebido. Se, na Provinha, a compreensão é medida sem requerer do sujeito a escrita de uma resposta, mas, sim, a leitura e seleção de uma única alternativa, entre quatro apresentadas, fica evidente que muitas das crianças das turmas que acompanhamos, provavelmente, não vivenciavam, no dia a dia de suas salas de aula, esse tipo de exercício de leitura.

Finalmente, e sem trazer algum novo dado animador, a Tabela 1 também revela que em apenas 2 das 108 jornadas de aulas que observamos houve a possibilidade de os estudantes do $2^{\circ}$ ano lerem o que quisessem. Isto é, somos levados a crer que a leitura de textos com livre escolha e para exclusivo deleite não fazia parte de seus processos de alfabetização.

Que estratégias de leitura as docentes praticaram com os alunos, nos poucos dias em que investiram em atividades de compreensão de leitura? Os resultados que encontramos aparecem na Tabela 2. Nela, registramos, inicialmente, a ocorrência das estratégias ou "habilidades" avaliadas pela Provinha ("Localizar informação explícita de um texto", "Identificar a finalidade de um texto", "Reconhecer o assunto de um texto" e "Inferir informação"), que julgamos, de fato, fundamentais para um leitor principiante. Mas computamos, também, a prática de outras estratégias (como "Ativar conhecimentos prévios", "Antecipar e/ou verificar hipóteses", "Emitir opinião sobre o texto", "Extrapolar o texto e discutir seu tema") que não são avaliadas pela Provinha. Na Tabela 2, encontramos a expressão quantitativa das evidências obtidas. 
Tabela 2 - Estratégias de leitura praticadas nas 12 turmas de alfabetização, durante os dias observados

\begin{tabular}{l|r|r|r|r|r|r|r|r|r|r|r|r|r|r|r}
\hline & C1 & C2 & C3 & C4 & Tot & R1 & R2 & R3 & R4 & Tot & J1 & J2 & J3 & J4 & Tot \\
\hline Localizar informação & 3 & - & 2 & - & 5 & 3 & 2 & 1 & - & $\mathbf{6}$ & 3 & 4 & - & - & $\mathbf{7}$ \\
\hline Identificar finalidade & - & - & - & - & - & - & - & - & - & - & 2 & - & - & - & $\mathbf{2}$ \\
\hline $\begin{array}{l}\text { Identificar } \\
\text { tema central }\end{array}$ & - & - & - & - & - & 1 & 2 & - & - & 3 & 1 & 4 & - & - & $\mathbf{5}$ \\
\hline Inferir informação & 3 & - & - & - & 3 & 2 & 1 & - & - & 3 & - & 3 & - & - & 3 \\
\hline Outras estratégias & 3 & 2 & 2 & 3 & $\mathbf{1 0}$ & 8 & 3 & 2 & 1 & $\mathbf{1 4}$ & 3 & 6 & - & - & $\mathbf{9}$ \\
\hline
\end{tabular}

$\mathrm{C}=$ turmas de Camaragibe; $\mathrm{R}=$ turmas de Recife; $\mathrm{J}=$ turmas de Jaboatão.

Número máximo de ocorrências em cada célula de turma =9; Número máximo de ocorrências no total de cada município = 36 . Fonte: Dados da pesquisa.

Elaboração do autor.

Se as análises feitas anteriormente, nessa seção, já indicavam uma baixa frequência de atividades de compreensão de leitura, o exame detalhado das poucas que ocorreram revela um quadro pouco animador: em 5 das 12 turmas, não registramos, em nenhum dia, a promoção de quaisquer das quatro estratégias de leitura avaliadas pela Provinha. Vimos que, mesmo a estratégia de "localizar informação explícita de um texto" - que tanto caracterizava as cartilhas e antigos livros didáticos das séries iniciais e que tendia a ser vista pelos críticos desses materiais como "limitada" ou "tradicional" - não foi praticada em 5 das 12 turmas que acompanhamos. Esse parece-nos um problema importante, porque, diferentemente dos críticos agora mencionados, julgamos, tal como demonstram alguns pesquisadores em psicologia cognitiva (Goigoux, 1991), que leitores principiantes precisam sim desenvolver a habilidade de recuperar informações explicitamente apresentadas na superfície textual, sobretudo se considerarmos que ainda estão consolidando um domínio das correspondências som-grafia da língua.

Como indica a Tabela 2, foi ainda mais rara a ocorrência de oportunidades para exercer as outras estratégias de leitura avaliadas pela Provinha. Não encontramos questões que levassem os alunos a "inferir informações" ou a "reconhecer o assunto de um texto" em 8 das 12 turmas acompanhadas. Por fim, não presenciamos situações que ajudassem as crianças a "identificar a finalidade de um texto" em 11 (!!!!) daquelas turmas. Lembremos que, tal como visto na Tabela 1, a leitura de textos ocorreu, em cada rede municipal, numa média global que variava aproximadamente entre 38 e $64 \%$ dos dias letivos. Parece, portanto, que era frequente ler textos e não investir na compreensão deles.

A formulação de questões (lembremos que eram feitas oralmente!!) que envolviam outras estratégias de leitura foi priorizada por várias das docentes que acompanhamos. Como só em duas turmas isso não aconteceu, fizemos uma análise mais minuciosa dos protocolos de observação de aula, a fim de verificar que outras estratégias de leitura eram, de fato, as mais praticadas naquelas situações (também infrequentes, cabe lembrar). Vimos que em apenas metade das turmas, em alguns dias, as crianças foram ajudadas a mobilizar conhecimentos prévios que poderiam auxiliá-las a compreender os textos e que só em duas salas de aula 
e em pouquíssimos dias foram levadas a formular e checar hipóteses com base no material a ser lido (e compreendido). Registrou-se, portanto, pouco cuidado em preparar os alunos para a leitura ou para buscar a continuidade da construção de sentidos, ao longo do texto.

Em uma das turmas, os alunos em cinco dos nove dias de observação foram chamados a extrapolar/discutir os temas sobre os quais os textos versavam. Nesse caso, entendemos que o ensino praticado não tratava os textos como objetos de linguagem escrita, cujos recursos linguísticos e sentidos o aprendiz precisava apreciar e reconstruir. Nesses casos, tal como observado por Marinho, Silva e Morais (2009), a escola parece usar os textos como pretexto para discutir temas, talvez em nome de respeitar as trajetórias de vida e conhecimentos dos alunos, mas sem, efetivamente, ajudá-los a compreender textos escritos.

Em síntese, cabe enfatizar, mais uma vez, que o pouquíssimo que se fazia (via de regra, oralmente) como atividade promotora de compreensão de leitura não envolvia as estratégias que a Provinha Brasil considera importante a escola desenvolver em seus alfabetizandos.

\section{EVIDÊNCIAS EMPÍRICAS 2 - O DESEMPENHO DOS ALUNOS EM COMPREENSÃO LEITORA MEDIDO PELA PROVINHA NO INÍCIO E NO FINAL DO ANO LETIVO}

Embora os resultados da Provinha sirvam para fazer um exame diagnóstico individual, também nos permitem calcular médias que expressem o percentual de acertos de cada uma das turmas observadas. Para simplificar as análises possíveis de apresentar nesta ocasião, resumimos esses dados na Tabela 3, na qual aparecem as médias percentuais obtidas pelas turmas nos quatro descritores de compreensão leitora avaliados nas edições da Provinha do início e do final do ano letivo de 2010. ${ }^{2}$ Apesar do escasso ensino de leitura recebido e das poucas oportunidades de exercitar estratégias de leitura que promovessem a compreensão dos textos lidos, constatamos, no início do ano, que em todas as cidades, para as quatro habilidades (ou descritores) analisadas(os), os acertos médios mais baixos se situavam em torno de 33\%. Uma exceção foi a habilidade de "inferência", na qual a turma R3 de Recife teve muitas dificuldades (apenas 10\% de acertos em média).

No final do ano letivo, ainda constatamos grandes variações entre as médias de acertos das turmas dos três municípios, para todos os descritores.

Apesar de as turmas pesquisadas em cada município pertencerem, via de regra, a apenas duas escolas com bons resultados na Prova Brasil do ano anterior, encontramos grandes variações nas médias das turmas de um mesmo município e, às vezes, de uma mesma escola. Assim, por exemplo, constatamos, no início do ano, no município de Jaboatão, nas turmas J2 e J3, as mais altas variações no descritor

2 Os resultados da turma J4 não serão analisados, porque na edição de dezembro a professora resolveu cada questão diante dos alunos, indicando-lhes as respostas corretas. 
"Localizar informações" ( $92 \%$ e 38\% de acertos médios) e, no final do ano, no descritor "Inferir informação" (95\% e 38\% de acertos).

Embora não queiramos estabelecer relações diretas de causa e efeito entre os tipos de ensino praticados e os resultados encontrados, chama a atenção o contraste entre os resultados das turmas 2 e 3 da cidade de Jaboatão. A turma J2 foi a que, entre as 12 pesquisadas, apresentou os mais altos resultados, em março e em novembro, e que se destacou, nas análises da seção anterior, por uma alta frequência de práticas de leitura de textos e por uma frequência muito maior que as demais turmas na prática de estratégias de leitura como a "Localização de informações" (4/9 aulas), a "Identificação de tema dos textos" (4/9 aulas) e a "Realização de inferências" (3/9 aulas). Noutra direção, os baixos resultados obtidos pelos alunos da turma J3 ocorreram numa sala de aula em que, durante as nove observações realizadas, não presenciamos qualquer atividade de interpretação de textos e só assistimos a leituras de textos pela mestra em duas aulas e uma única vez pelos alunos.

Tabela 3 - Médias percentuais de acertos nos quatro descritores que mediam compreensão de leitura no início e no fim do ano letivo

\begin{tabular}{|c|c|c|c|c|c|c|c|c|c|c|c|c|}
\hline & C1 & $\mathrm{C} 2$ & C3 & C4 & R1 & $\mathrm{R} 2$ & R3 & R4 & $\mathrm{J} 1$ & $\mathrm{~J} 2$ & J3 & $\mathrm{J} 4$ \\
\hline $\begin{array}{l}\text { (D6) Localização de } \\
\text { Informação MAR. }\end{array}$ & $39 \%$ & $32 \%$ & $34 \%$ & $55 \%$ & $37 \%$ & $55 \%$ & $35 \%$ & $40 \%$ & $56 \%$ & $92 \%$ & $38 \%$ & - \\
\hline $\begin{array}{l}\text { (D6) Localização de } \\
\text { Informação NOV. }\end{array}$ & $36 \%$ & $59 \%$ & $57 \%$ & $45 \%$ & $32 \%$ & $62 \%$ & $35 \%$ & $50 \%$ & $87 \%$ & $76 \%$ & $44 \%$ & - \\
\hline $\begin{array}{l}\text { (D7) Reconhecer assunto } \\
\text { de um texto MAR. }\end{array}$ & $60 \%$ & $50 \%$ & $54 \%$ & $25 \%$ & $40 \%$ & $40 \%$ & $35 \%$ & $63 \%$ & $63 \%$ & $90 \%$ & $75 \%$ & - \\
\hline $\begin{array}{l}\text { (D7) Reconhecer assunto } \\
\text { de um texto NOV. }\end{array}$ & $58 \%$ & $59 \%$ & $77 \%$ & $60 \%$ & $57 \%$ & $65 \%$ & $50 \%$ & $63 \%$ & $85 \%$ & $76 \%$ & $69 \%$ & - \\
\hline $\begin{array}{l}\text { (D8) Identificação de } \\
\text { Finalidade MAR. }\end{array}$ & $57 \%$ & $36 \%$ & $69 \%$ & $40 \%$ & $65 \%$ & $60 \%$ & $40 \%$ & $40 \%$ & $65 \%$ & $80 \%$ & $56 \%$ & - \\
\hline $\begin{array}{l}\text { (D8) Identificação de } \\
\text { Finalidade NOV. }\end{array}$ & $47 \%$ & $68 \%$ & $46 \%$ & $60 \%$ & $55 \%$ & $72 \%$ & $30 \%$ & $50 \%$ & $78 \%$ & $88 \%$ & $50 \%$ & - \\
\hline (D10) Inferência MAR. & $37 \%$ & $32 \%$ & $42 \%$ & $32 \%$ & $32 \%$ & $42 \%$ & $10 \%$ & $45 \%$ & $63 \%$ & $65 \%$ & $44 \%$ & - \\
\hline (D10) Inferência NOV. & $47 \%$ & $73 \%$ & $38 \%$ & $70 \%$ & $35 \%$ & $65 \%$ & $30 \%$ & $45 \%$ & $75 \%$ & $95 \%$ & $38 \%$ & - \\
\hline
\end{tabular}

Fonte: Dados da pesquisa.

Elaboração do autor.

Se considerarmos os resultados do final do ano letivo, dois aspectos chamam-nos a atenção. Em primeiro lugar, parece-nos preocupante o fato de algumas turmas concluírem o segundo ano letivo de alfabetização com tal número de alunos apresentando ainda tantas dificuldades nos quatro descritores básicos avaliados pela Provinha Brasil. Considerando que quase não presenciamos nenhum tipo de atividade em que o ensino se ajustasse aos níveis de aprendizagem dos alunos, nos indagamos o que esperar de uma turma como R3, na qual, no final do ano, em média, os alunos só acertavam 35\% dos itens relativos a "Localizar informação explícita de um texto", 30\% dos que exigiam "Identificar a finalidade de um texto", apenas a metade das questões que pediam para "Reconhecer o assunto de um 
texto", e só 30\% das questões em que deviam "Inferir informação" não explicitadas na superfície dos textos.

Um segundo aspecto que nos chamou a atenção foi o fato de, em diferentes turmas, termos constatado uma "piora" no rendimento médio dos alunos. Vejamos que, mesmo num grupo-classe que se destacou, desde o início do ano, por altos desempenhos, como foi o caso da turma J2, verificamos, no final do ano, decréscimos superiores a $14 \%$ nas médias percentuais alcançadas nos descritores "Localizar informação"e "Reconhecer o assunto". No conjunto das 11 turmas analisadas, considerando os quatro descritores, constatamos que em apenas três (C2, R2 e R4) os rendimentos médios, ao final do ano, foram sempre superiores ou idênticos aos mensurados no mês de março. $\mathrm{O}$ fato de termos encontrado uma maior frequência de casos nos quais o desempenho final era inferior ao inicial nos levou a examinar mais qualitativamente a complexidade dos itens da Provinha, tema que trataremos na seção seguinte.

\section{EVIDÊNCIAS EMPÍRICAS 3 - AS OSCILAÇÕES DE COMPLEXIDADE NOS ITENS DA PROVA NUMA MESMA EDIÇÃO E EM DIFERENTES EDIÇÕES}

Professor, o que é que a gente faz quando vê que, em muitas turmas da rede, os alunos se saíram pior no final do ano do que em março? Minhas professoras disseram que a prova de dezembro foi mais difícil. (Indagação formulada por uma diretora de ensino de um pequeno município de Pernambuco, em encontro de formação continuada que tratava da Provinha, em fevereiro de 2010)

Se a Provinha Brasil se apresenta como instrumento para medir, no início e no final do $2^{\circ}$ ano do ensino fundamental, os conhecimentos dos aprendizes a respeito do sistema alfabético e sua capacidade de compreensão leitora, para fazer uma comparação do desempenho dos alunos, naquelas duas ocasiões, fica subentendido que os dois testes teriam idêntico nível de complexidade, embora isso não seja afirmado nos documentos que, desde 2008, constituem o kit do exame enviado às escolas. Tampouco encontramos, nos documentos de divulgação formulados pelo INEP, explicações sobre como se controlam os níveis de complexidade dos itens usados a cada edição da prova ou que, numa mesma edição, avaliam um mesmo descritor.

Docentes envolvidos na elaboração de avaliações de compreensão de leitura e pesquisas que analisam o processo de medição da compreensão leitora indicam a extrema dificuldade de se conseguir estabelecer equivalências de dificuldade, por exemplo, entre questões de compreensão leitora que tratam de uma mesma habilidade de leitura, mas que são elaboradas sobre textos diferentes. A dificuldade persiste mesmo quando o elaborador dos instrumentos usa textos pertencentes a um mesmo gênero textual.

Tal dificuldade levou alguns pesquisadores do ensino e aprendizado da alfabetização a optar por, propositalmente, aplicarem um mesmo instrumento em dois momentos da escolarização, a fim de garantir a comparabilidade das medidas 
obtidas (Kaufman; Gallo; Wuthenau, 2010). No caso da proposta formulada por essas autoras para crianças argentinas, estudantes que frequentam os três anos do ciclo inicial do ensino fundamental são submetidos aos mesmíssimos textos, quando se trata de avaliar sua compreensão leitora.

A fim de verificar a existência ou não de oscilações no grau de dificuldade dos itens da Provinha Brasil, tal como sugeriam certas evidências tratadas na seção anterior, optamos por comparar os itens usados nas duas edições do exame divulgadas durante o ano letivo de 2010, priorizando os descritores que avaliavam compreensão de textos: "Localizar informação explícita de um texto", "Reconhecer o assunto de um texto", "Identificar a finalidade de um texto" e "Inferir informação" (Morais; Leal; Pessoa, 2011). Confirmamos que o nível de complexidade variava e que ele, em princípio, poderia ser influenciado por diferentes fatores e por uma combinação deles. Tal influência podia ser provocada pelo gênero e suporte textuais, pela presença explícita ou não de determinadas palavras ou expressões na superfície do texto, pela extensão do que a criança teria de ler para responder à questão, pela plausibilidade dos distratores e pela presença ou não de palavras da superfície do texto entre os distratores.

Na mesma direção, Porto (2011), ao utilizar itens da Prova Brasil, para analisar o desempenho de alunos do $5^{\circ}$ ano do ensino fundamental, também observou que os itens usados pelo INEP para avaliar uma mesma habilidade de leitura ("inferir", "localizar informações na superfície do texto" etc.) variavam bastante quanto ao grau de dificuldade que assumiam, em diferentes edições daquele exame nacional. A autora verificou que na avaliação específica de certos descritores seus sujeitos tiveram um desempenho médio satisfatório, ao responderem a uma versão da Prova Brasil, no início do ano, e que pioraram bastante no rendimento revelado em outra versão da prova, ao final do ano letivo. Como o ensino de leitura praticado naquela turma era de comprovada qualidade, a autora sugeriu que $o$ tema - variação do nível de dificuldade dos itens que avaliam descritores - seja tratado com cuidado pelo MEC-INEP, já que os "ranqueamentos" praticados com base em tal exame pressupõem uma comparabilidade dos resultados ao longo dos anos. No caso da Provinha, embora não estejam previstos "ranqueamentos", a falta de controle do nível de dificuldade das questões pode causar problemas na medição dos conhecimentos dos aprendizes, tal como aponta a epígrafe que abriu esta seção.

\section{CONSIDERAÇÕES E RECOMENDAÇÕES FINAIS}

As evidências tratadas nas seções anteriores atestam, de início, uma grande distância entre o ensino de compreensão de leitura praticado nas salas de aula (de $2^{\circ}$ ano!) que acompanhamos e o que era avaliado pelas edições da Provinha Brasil de 2010, naquele âmbito do processo de alfabetização. O divórcio constatado parece sugerir não a "inadequação", "fragmentação" ou "descontextualização" do exame elaborado pelo INEP, mas uma necessidade urgente de qualificarmos as práticas de ensino de alfabetização desenvolvidas em nossas redes de ensino. O fato de termos constatado um ensino de compreensão leitora tão escasso e pouco eficiente, durante muitas das 
108 jornadas escolares de grupos-classe que observamos - e que, recordemos, eram turmas que pertenciam a escolas bem avaliadas em suas redes de ensino -, é por nós interpretado como indicador de uma urgente e imperiosa discussão, em âmbito nacional, dos currículos que desejamos praticar em nosso país. Parece-nos necessário discutir todos os currículos da educação básica. No caso da alfabetização, precisamos definir quais currículos desejamos para os anos finais da educação infantil e para o ciclo inicial de três primeiros anos do ensino fundamental. $\mathrm{O}$ estabelecimento de metas claras de aprendizagem para os alunos, dos 4 aos 8 anos de idade, parece-nos uma questão de responsabilidade para com a democratização da qualidade da educação pública.

Considerando, ainda, a distância constatada entre o ensino praticado em muitas das turmas por nós pesquisadas e os conhecimentos avaliados pela Provinha, parecem-nos infundadas as críticas feitas por determinados estudiosos (por exemplo, Esteban, 2009), ao acusarem tal exame de adotar uma concepção "fragmentada" do processo de alfabetização, por avaliar, com distintos eixos e descritores, habilidades que concernem, especificamente, ao aprendizado do sistema de escrita alfabética (alfabetização em sentido estrito) e ao domínio de práticas de compreensão de textos (letramento, obviamente sem incluir práticas de produção de textos, o que já criticaremos).

Desde o final da década de 1990 (Soares, 1998), temos construído um expressivo consenso, entre os que pesquisam e ensinam no âmbito da alfabetização, sobre a necessidade de tratarmos como distintos, mas interligados, os conceitos de alfabetização e letramento. Dispomos, hoje, de bastante consenso sobre a necessidade de não só alfabetizar, mas também de letrar (isto é, ensinar a compreender e produzir textos escritos), já na etapa inicial de alfabetização. Não nos parece sensato, portanto, criticar a Provinha por avaliar habilidades de letramento tão básicas como as capacidades de localizar informações explícitas ou de inferir informações em textos curtos. Se, em muitas salas de aula do país, tais habilidades ainda não são praticadas, às vezes sequer no $3^{\circ}$ ano do ciclo de alfabetização (Oliveira, 2010), cremos ser inadiável discutirmos o que queremos fazer para acabar com o apartheid educacional que tem mantido sistemas de ensino tão distintos, do ponto de vista qualitativo, para os alunos das camadas populares e de outros segmentos (camadas médias e burguesia). ${ }^{3}$

Apesar de, em todas as escolas por nós pesquisadas, a Provinha ter sido aplicada no início e no final do ano letivo, não constatamos, na quase totalidade das aulas observadas, qualquer iniciativa de atendimento às necessidades diversificadas dos aprendizes, formuladas com base na Provinha ou em quaisquer outros dispositivos diagnósticos. A constatação de que as atividades de ensino-aprendizagem praticadas eram, via de regra, coletivas e padronizadas para todos os alunos de cada grupo-classe nos levam a três reflexões.

A primeira é a constatação de que parece ingênuo atribuir a um exame externo, como a Provinha, o poder de, sem mais, fazer currículo, de induzir os professores

3 Vale ter em mente que, se durante o ano letivo, algumas das professoras pouco praticaram com seus alunos as habilidades de compreensão básicas mensuradas pela Provinha, tampouco as verificavam nas avaliações que realizavam no dia a dia. 
a priorizarem o ensino de determinados conteúdos ou habilidades. Sem negar que isso ocorra em outras escolas e salas de aula, não foi o que verificamos nas turmas das três redes públicas de ensino que acompanhamos. A grande diversidade de formas de ensinar que encontramos, dentro de cada rede, demonstra que os professores parecem definir suas prioridades e encaminhamentos didáticos sem se pautar por acordos coletivos formulados com seus pares e, muito menos, pela matriz de referência da Provinha.

Uma segunda constatação é a de que, se a realização de diagnósticos é um saudável princípio para ajustar o ensino às necessidades dos alunos, a aplicação e o levantamento do rendimento dos aprendizes, com base na Provinha, não têm o poder miraculoso de mudar a cultura escolar historicamente construída, que nunca se voltou ao tratamento da heterogeneidade na sala de aula. Noutras palavras, não podemos querer garantir o direito à alfabetização efetiva e de qualidade apenas nos aprimorando na aplicação de exames diagnósticos. Sem políticas de formação continuada, de melhoria das condições de trabalho dos alfabetizadores e sem definição clara de bases curriculares, o discurso do respeito à diversidade, que marca e diferencia a organização escolar em ciclos, permanece um belo discurso a produzir distorções ideológicas que mascaram a realidade.

A terceira reflexão é, portanto, sobre a urgência de implantação de políticas públicas que assegurem o atendimento da diversidade no interior das salas de aula. A implementação de apoios permanentes à atuação dos alfabetizadores responsáveis pelos alunos dos três primeiros anos de alfabetização precisa ser tomada não só como medida de garantia do direito à aprendizagem pelos alfabetizandos, mas de garantia das adequadas condições de exercício da docência. O que temos visto, infelizmente, é o avanço de "programas de correção de fluxo" que, vendidos às redes públicas por grupos privados, mantêm esquemas remediadores e de exclusão (Dourado, 2010).

Quanto às limitações do exame Provinha, constatadas com base em nosso acompanhamento, elencaremos, em seguida, o que acreditamos constituir elementos passíveis de revisão, para que possam dar conta de sua função diagnóstica original. Questionamos, de início, o fato de um exame que se anuncia com o objetivo de cumprir apenas tal finalidade omitir medidas sobre os conhecimentos que os alfabetizandos construíram a respeito das habilidades de escrever palavras e produzir textos. Entendemos que todo alfabetizador precisa saber como cada um de seus alunos está avançando naquelas duas habilidades de uso da língua escrita e de sua notação, para, adequadamente, ajustar o ensino às necessidades dos alfabetizandos. Recordamos que, em sua primeira edição (no primeiro semestre de 2008), a Provinha incluiu itens de escrita de palavras que, sem maiores explicações, foram abandonados nos anos seguintes, mas que nunca mediram a capacidade das crianças de produzirem pequenos textos, algo que, hoje, é uma expectativa consensual entre os que compartilham uma concepção de alfabetizar letrando, sobretudo se o processo de alfabetização é concebido como algo que se consolida ao longo de três anos letivos.

No bojo de tal revisão, propomos um amplo debate sobre a matriz de referência da Provinha (e de todas as outras avaliações em larga escala adotadas pelo MEC). Embora nosso entendimento seja o de que a maioria dos atuais descritores que compõem a matriz da Provinha é bastante pertinente, julgamos ser obrigatório 
vivenciarmos uma discussão nacional sobre tal matriz, associada ao já cobrado debate sobre a definição de uma base curricular nacional para a alfabetização. Interpretamos que a ausência de tal debate não só revelaria autoritarismo, mas dificultaria a mudança de práticas excludentes na escola, que tem tido dificuldade em alfabetizar, com qualidade e em tempo adequado, muitos dos filhos das camadas populares.

Em segundo lugar, sugerimos que o tratamento dos dados medidos abandone, radicalmente, a lógica de alocação dos aprendizes em "escalas de níveis", tal como vêm sugerindo os kits de interpretação de resultados divulgados pelo INEP, a cada semestre. Assim como argumentamos em outra ocasião (Morais; Leal; Pessoa, 2011), a construção daquelas escalas não tem sustentação teórica, porque pressupõe uma gradação linear do nível de dificuldade das habilidades de leitura de palavras, leitura de frases e leitura de textos, que são medidas pela Provinha. Do ponto de vista teórico, pressupõe, além disso e também equivocadamente, que certas habilidades de compreensão leitora (como "Localizar informações explícitas em um texto") seriam sempre e obrigatoriamente menos complexas que outras (como "Inferir informações de um texto"), desconsiderando a influência de todos os fatores que elencamos na seção anterior. Do ponto de vista pedagógico, tememos que o tratamento quantitativo (somar pontos relativos a habilidades diferentes para situar o aluno numa escala) tire o foco do que deve ser o objetivo do exame: diagnosticar exatamente quais habilidades cada aluno já desenvolveu e quais precisa ser ajudado a aprender.

Ainda no que diz respeito a cuidados com a elaboração do exame, recordamos a necessidade de serem buscados controles mais efetivos do nível de complexidade dos itens que, a cada edição, medem o desempenho das crianças em cada uma das habilidades. A atual falta de controle parece criar problemas para a comparabilidade dos resultados obtidos por cada aluno, no início e no final do ano letivo.

Finalmente, recomendamos que os professores sejam, ao lado dos gestores, definitivamente incluídos em todas as etapas de aplicação e de análise dos resultados da Provinha e que, com a ajuda de coordenadores pedagógicos e gestores, possam dispor de mecanismos efetivos para planejar e realizar um ensino que considere as necessidades dos aprendizes. Interpretamos que, assim como observou Oliveira (2010), a não realização desse ensino ajustado, infelizmente, seria uma marca da grande maioria das redes públicas que, atualmente, tem o ensino de alfabetização organizado em ciclos. A luta pelo cumprimento efetivo daquela promessa fundadora da lógica dos ciclos, que tem como princípio o respeito à diversidade dos ritmos de aprendizagem dos educandos, constitui não só questão de coerência pedagógica, mas também de responsabilidade política.

\section{REFERÊNCIAS}

Albuquerque, Eliana Borges Correia; Ferreira, Andrea Tereza Brito; Morais, Artur Gomes de. Learning the alphabetic writing system: the effects of different teaching practices in Brazil. In: SigWriting 2006, Antwerp. University of Antwerp, 2006. 
.; Morais, Artur Gomes de; Ferreira, Andrea Teresa Brito. As práticas cotidianas de alfabetização: o que fazem as professoras? Revista Brasileira de Educação, Rio de Janeiro, ANPEd; Campinas, Autores Associados, v. 13, n. 38, p. 252-264, maio/ago. 2008.

Arroyo, Miguel. Reflexões sobre a Provinha Brasil.Jornal Letra A, Belo Horizonte, Centro de Alfabetização, Leitura e Escrita da UFMG (CEALE), Edição Especial, p. 3, jun./jul. 2008.

Brasil. MEC/INEP. Provinha Brasil-reflexões sobre a prática. Brasília, MEC/INEP, 2008a.

.Provinha Brasil-guia de correção e interpretação de resultados. Brasília, MEC/ INEP, 2008b.

Cruz, Magna Carmo Silva. Alfabetizar letrando: alguns desafios do $1^{\mathrm{o}}$ ciclo no ensino fundamental. 2008. Dissertação (Mestrado em Educação) - Universidade Federal de Pernambuco, Recife, 2008.

; Albuquerque, Eliana Borges Correia. Alfabetização e letramento no $1^{\circ}$ ciclo: o que as crianças aprendem sobre a escrita a cada ano? Revista Brasileira de Estudos Pedagógicos, Brasília, Editora do INEP, v. 92, n. 230, p. 126-147, jan./abr. 2011.

Cunha, Alessandra. Professoras alfabetizadoras e a língua materna: relacionando as expectativas, os conteúdos e a forma de ensiná-los. In: Reunião AnuAl da ANPEd, 28., 2005, Caxambu. Anais... Caxambu: Associação Nacional de Pesquisa e Pós-Graduação em Educação. Disponível em: <http://www.anped.org.br/reunioes/28/textos/gt10/ gt101439int.rtf>. Acesso em: 19 maio 2009.

Dourado, Viviane Carmem de Arruda. O atendimento a crianças com dificuldades de aprendizagem: práticas de professores e material didático do programa "Se Liga". 2010. Dissertação (Mestrado em Educação) - Universidade Federal de Pernambuco, Recife, 2010.

Esteban, Maria Teresa. Provinha Brasil: desempenho escolar e discursos normativos sobre a infância. Sísifo-Revista de Ciências da Educação, n. 9, p. 47-56, maio/ago. 2009. Disponível em: <http://sisifo.fpce.ul.pt>. Acesso em: 1 out. 2011.

Fernandes, Domingos. Para uma teoria da avaliação formativa. Revista Portuguesa de Educação, Lisboa, Editora da Universidade de Lisboa, v. 19, n. 2, p. 21-50, set. 2006.

Ferreiro, Emilia; Teberosky, Ana. Los sistemas de escritura en el desarrollo del niño. México: Siglo XXI Eds., 1979.

Frigotto, Edith. Leitura e escrita nos ciclos de formação: existe algum avanço? In: Reunião Anual da Anped,28., 2005, Caxambu. Anais... Caxambu: Associação Nacional de Pesquisa e Pós-Graduação em Educação, 2005. Disponível em: http://www.anped.org. br/reunioes/28/textos/gt10/gt101418int.rtf>. Acesso em: 19 maio 2009.

Goigoux, Roland. Les 5-8 ans et les modèles interactifs. La lecture au cycle des aprentissages. In: Bentolila, Alain; Chevalier, Brigitte; Falcoz-Vigne, Danièle. La lecture: aprprentissage, évaluation, prefectionnement. Paris: Nathan, 1991. 
Kaufman, Ana Maria; Gallo, Adriana; Wuthenau, Celina. Como avaliar aprendizagens em leitura e escrita? Um instrumento para o primeiro ciclo da escola primária. In: Cavalcanti, Zélia (Org.). 30 olhares para o futuro. São Paulo: Escola da Vila, 2010.

Mamede, Inês. Professoras alfabetizadoras e suas leituras teóricas. In: Reuniño Anual da Anped, 26., Caxambu. Anais... Caxambu: Associação Nacional de Pesquisa e Pós-Graduação em Educação, 2003. Disponível em: <http://www.anped.org.br/ reunioes/26/trabalhos/inescristinademelomamede.rtf >. Acesso em: 19 maio 2009.

Marinho, Adriett de Luna Silvino Marinho; Silva, Jane Rafaela Pereira; Morais, Artur Gomes de. Ensino de compreensão leitora: práticas de ensino e propostas dos livros didáticos destinados à EJA. 2009. Trabalho de Conclusão de Curso (Graduação em Pedagogia) - Universidade Federal de Pernambuco, Recife, 2009.

Monteiro, Hilda. Aprendizagens de uma professora alfabetizadora após a formação Inicial. In: Reunião Anual da ANPEd, 27., Caxambu. Anais... Caxambu: Associação Nacional de Pesquisa e Pós-Graduação em Educação, 2004. Disponível em:<http:// www.anped.org.br/reunioes/27/gt10/t106.pdf>. Acesso em: 19 maio 2009.

Morais, Artur Gomes de. Discursos recentes sobre alfabetização no Brasil: por que é preciso ir além da discussão sobre velhos métodos? In: Silva, Aída Maria Monteiro da; Melo, Márcia Maria de Oliveira (Orgs.). Educação, questôes pedagógicas e processos formativos: compromisso com a inclusão social. 1. ed. Recife: Edições Bagaço, 2006, v. 1. p. 439-454.

.; Leal, Telma Ferraz; Pessoa, Ana Cláudia. Provinha Brasil - sua recepção pelos docentes e usos na alfabetização. Relatório final de atividades apresentado ao INEP. Recife: Universidade Federal de Pernambuco, 2011.

.; Leal, Telma Ferraz; Albuquerque, Eliana Borges Correia. Provinha Brasil: monitoramento de aprendizagens e formulação de políticas educacionais. Revista Brasileira de Política e Administração da Educação, Porto Alegre, Editora da UFRGS, v. 25, n. 2, p. 301-320, maio/ago. 2009.

Oliveira, Solange Alves de. O sistema de notação alfabética como objeto de ensino e de avaliação num regime ciclado: concepções da prática. In: Reuniẽo Anual DA ANPEd, 29., 2006, Caxambu. Anais... Caxambu: Associação Nacional de Pesquisa e Pós-Graduação em Educação, 2006. Disponível em: <http://www.anped.org.br/reunioes/29ra/trabalhos/ trabalho/GT10-2314--Int.pdf2006>. Acesso em: 19 maio 2009.

. Progressão das atividades de língua portuguesa e o tratamento dado à heterogeneidade das aprendizagens: um estudo da prática docente no contexto dos ciclos. 2010. Tese (Doutorado em Educação) - Universidade Federal de Pernambuco, Recife, 2010.

Porto, Cynthia Cybelle Rodrigues. Práticas de ensino de compreensão de leitura e conhecimentos de alunos do último ano do ensino fundamental 1.2011. Dissertação (Mestrado em Educação) Universidade Federal de Pernambuco, Recife, 2011.

SoAres, Magda. Letramento: um tema em três gêneros. Belo Horizonte: Autêntica, 1998. . A reinvenção da alfabetização. Presença Pedagógica, Belo Horizonte, Dimensão, v. 9 , n. 52, p. 1-21, jul./ago. 2003. 


\section{SOBRE O AUTOR}

Artur Gomes de Morais é doutor em psicologia pela Universidade de Barcelona. Professor titular da Universidade Federal de Pernambuco (UFPE). E-mail: agmorais@uol.com.br

Recebido em janeiro de 2012

Aprovado em julho de 2012 


\section{ARTUR GOMES DE MORAIS}

\section{Políticas de avaliação da alfabetização: discutindo a Provinha Brasil}

A fim de discutir a Provinha Brasil, exame que avalia conhecimentos das crianças brasileiras que estão alfabetizando-se, estudamos as relações entre ensino recebido e desempenho na Provinha. Acompanhamos, durante um ano letivo, 12 turmas de $2^{\circ}$ ano de três redes públicas e analisamos o rendimento daqueles alunos na Provinha, no início e no final do ano escolar. Constatamos que o ensino de compreensão de leitura pouco ocorria em muitas das salas de aula observadas e que, quando tinha lugar, as habilidades praticadas não eram as avaliadas pela Provinha. Verificamos, também, uma variação muito grande nos desempenhos das turmas no interior das escolas de uma mesma rede e de diferentes redes de ensino, bem como uma oscilação no nível de complexidade dos itens usados pelo exame a cada edição. Constata-se, assim, a necessidade de discutirmos os currículos brasileiros de alfabetização, a matriz da Provinha e de envolvermos os professores na formulação e no uso daquele exame.

Palavras-chave: Provinha Brasil; alfabetização; avaliação.

Policies of reading instruction evaluation: discussing the case of Provinha Brasil

In order to discuss Provinha Brasil, an exam which evaluates the performance of Brazilian children who are learning how to read and write, we have studied the relationships between instruction and performance on Provinha. During a school year, we observed classes in twelve 2nd grade classrooms of public schools of three cities and we 
analyzed students' performance on Provinha at the beginning and at the end of the school year. We found out that reading comprehension instruction seldom took place in many of the classrooms we observed and that reading abilities taught were not those evaluated by Provinha. We also found a strong variation in class groups' performances inside the same school and between schools, as well as a variation in the complexity of the items used by the test in each of its editions. Thus, we concluded that it is necessary to discuss the Brazilian reading instruction curricula and the abilities measured by Provinha. It is also necessary to involve teachers in the development and use of that exam.

Keywords: Provinha Brasil; reading instruction; evaluation.

\section{Políticas de evaluación de la alfabetización: el caso de la Provinha Brasil}

Para discutir la Provinha Brasil, un examen que evalúa los conocimientos de los niños brasileños durante la alfabetización, estudiamos las relaciones entre la enseñanza recibida y el desempeño en la Provinha. Durante un año lectivo acompañamos $12 \mathrm{grupos} \mathrm{de} 2^{\circ}$. año de escuelas de tres municipalidades y analizamos el desarrollo de aquellos alumnos en la Provinha, al inicio y al final del año escolar. Se constató que la enseñanza de comprensión lectora apenas ocurría en varias aulas observadas y que, cuando sucedia, las habilidades practicadas no eran aquellas evaluadas por la Provinha. También comprobamos una gran variación en los desempeños de alumnos en el interior de una misma escuela y entre las escuelas, además de una variación del nivel de complejidad de los items usados por el examen en cada una de sus ediciones. Se concluye, así, la necesidad de discutir los currículos brasileños de alfabetización y la matriz de la Provinha e incluir a los maestros en la formulación y en el uso de dicho examen.

Palabras clave: Provinha Brasil; alfabetización; evaluación. 